\title{
Sieger, Besiegte oder wer schreibt Geschichte
}

(Festvortrag in der öffentlichen Sommersitzung am 15. Mai 2009)

\author{
Christian Meier \\ Träger der Lichtenberg-Medaille 2009 \\ Laudatio auf Christian Meier
}

Sehr geehrter Herr Präsident, sehr geehrter Herr Meier, sehr geehrte Damen und Herren!

Die Lichtenberg-Medaille ist die höchste Auszeichnung, die unsere Akademie zu vergeben hat. An ihr sind alle Akademiemitglieder unmittelbar beteiligt. Verliehen wird sie solchen Gelehrten, die sich in ihrem Fachgebiet besonders ausgezeichnet haben, außerdem aber über ihr engeres Fachgebiet hinaus in eine breitere Öffentlichkeit wirken. Diese beiden Gesichtspunkte müssen also bei Vorschlägen zur Verleihung der Lichtenberg-Medaille bedacht und berücksichtigt werden.

Was den ersten Aspekt angeht, so wäre es vermessen, wenn ich mir zu ihm ein Urteil anmaßen wollte, da Christian Meier Historiker ist, während ich als Philologe und Sprachwissenschaftler arbeite. Daher erlaube ich mir, die wichtigsten Passagen aus dem Verleihungsvorschlag zu zitieren, der von Professor Gustav Adolf Lehmann verfaßt worden ist, dem Vertreter des Faches Alte Geschichte in unserer Akademie.

„Schon das erste, aus der Habilitationsschrift (1962 in Frankfurt am Main vorgelegt) erarbeitete Buch von Christian Meier „Res publica amissa. Eine Studie zur Verfassung und Geschichte der späten römischen Republik“ (Wiesbaden 1966) war ein großer Wurf und hat weit über das Fach Alte Geschichte hinaus ein lebhaftes Echo gefunden. Statt der allzu einfachen und selbstsicheren Antworten in der bis dahin geführten Forschungsdiskussion wurde hier zur Geschichte der späten Römischen Republik nach der Dictatur Sullas das faszinierende Bild eines politischen Zerfalls- und Verwandlungsprozesses entworfen, der sich gleichsam hinter dem Rücken der politisch und militärisch handelnden Akteure und Kräfte in Rom vollzog. Seine These von einem Untergang der weltbeherrschenden Republik nicht in einer „Römischen Revolution“- so Theodor Mommsen und später 
Alfred Heuß -, sondern in einer anhaltenden zermürbenden „Krise ohne Alternative" hat Christian Meier danach in einer ganzen Reihe scharfsinniger Untersuchungen und glänzend geschriebener Essays - sowohl von der Ebene einer sehr genauen Kenntnis einschlägiger Quellenzeugnisse aus als auch mit dem Rüstzeug einer modernen mentalitätsgeschichtlichen Theorie - verteidigt und weiter ausgebaut: Hier wurde die inzwischen berühmt gewordene Formel von der „Ohnmacht des allmächtigen Dictators Caesar“ gefunden, dem in Rom am Ende zwar überlegene „Macht in den Verhältnissen, aber nicht über die Verhältnisse" zu Gebote stand. Den Gipfelpunkt und Abschluß dieser Studien bildete die große Caesar-Biographie (von 1982), die Meiers Werk und Anliegen auch einer breiten außerfachlichen Öffentlichkeit bekannt machte - weit über „die Provinz des Historikers" (und erst recht des Altertumswissenschaftlers) hinaus, um eine scharfzüngige Formulierung von Christian Meier selbst zu verwenden.

Neben den Darstellungen und Studien über die großen Fragen in der Geschichte der Römischen Republik stehen bei Meier - in der Tradition seines 1961 verunglückten Heidelberger Lehrers Hans Schaefer - Abhandlungen mit neuen methodischen und sachlichen Ansätzen zur antiken griechischen Staatenwelt - zur archaischen Epoche der Herausbildung des hellenischen Polisstaates mit seinen charakteristischen Lebens- und Verfassungsformen ebenso wie zur klassischen Demokratie Athens im 5. Jh. v. Chr. Jahrzehntelang betriebene gelehrte Arbeit, mannigfache Interpretationen und Vorstudien hat Christian Meier auf diesem Gebiet in seinen großen Werken „Die politische Kunst der griechischen Tragödie“ (1988) und „Athen. Ein Neubeginn der Weltgeschichte“ (1993) zu einer eindrucksvollen Synthese zusammengefaßt. Historisch-theoretische und mentalitätsgeschichtliche Fragestellungen stehen im Mittelpunkt eines Versuchs, über die großen Themen der Tragödien die Vorstellungskraft und die inneren Lebensformen Athens und seiner hier geistig „unterfangenen“ Demokratie näher zu erfassen. In der Hauptsache ging es darum, den buchstäblich lebensnotwendigen Zusammenhang zwischen der Politik der noch ganz „neuen“, demokratisch regierten Großmacht Athen (zwischen Perserkriegen und Peloponnesischem Krieg) und der Tragödienkultur der athenischen Festgemeinde und Bürgerschaft aufzuzeigen. Darüber hinaus sind beide Bücher - zusammen mit der großen Caesar-Biographie - Meisterwerke einer modernen "Geschichtsschreibung aus der Forschung heraus“ und mit literarischem Anspruch.

Soeben hat Christian Meier einen gewichtigen Teil einer geplanten Gesamtdarstellung zur "Geschichte der Antike“ (im Rahmen einer mehrbändigen „Geschichte Europas“) vorgelegt; im Mittelpunkt steht hier der viel- 
schichtige Prozeß der „Entstehung der hellenischen Poliswelt“ zwischen dem Ende der mykenisch-frühgriechischen Epoche und dem Vorabend der Perserkriege (am Ende des 6. Jh. v. Chr.): dieser grundlegende Neubeginn in der Geschichte des Altertums wird in tiefgreifenden Interpretationen und historischen Analysen auf höchstem Reflexionsniveau als ein faszinierendes „Praeludium“ vor der spezifischen Geschichte Europas aufgefaßt und nach vielen Richtungen hin ausgedeutet: „Kultur, um der Freiheit willen. Griechische Anfänge - Anfang Europas?", München 2009“.

Wäre Christian Meier „nur“ ein brillanter Althistoriker, „nur“ ein herausragender Vertreter seiner akademischen Spezialdisziplin, so wäre er für die Verleihung der Lichtenberg-Medaille nicht in Frage gekommen. Er muß, so fordert es die Satzung, auch in eine breitere Öffentlichkeit hinein wirken. Ich könnte es mir leicht machen und mich mit dem Hinweis darauf begnügen, daß die Wirkung des Werkes von Christian Meier in eine breitere Öffentlichkeit hinein auf der Hand liegt: Angefangen bei „Res publica amissa", über die Caesar-Biographie bis hin zu der bisher letzten Monographie „Griechische Anfänge - Anfang Europas?" sind alle Bücher von Christian Meier weit über den Umkreis der Fachleute hinaus lebhaft rezipiert und diskutiert worden. In aller Unbescheidenheit darf ich mich selbst als Zeugen für eine solche Breitenwirkung benennen, da ich sowohl „Res publica amissa" als auch die Caesar-Biographie wie auch andere Arbeiten von Christian Meier gelesen habe, und zwar nicht erst, der Pflicht gehorchend, bei der Vorbereitung der von mir hier vorzutragenden Laudatio. Es ist aber natürlich erforderlich, daß wir uns Klarheit darüber zu verschaffen suchen, warum sich Christian Meier nicht als „bloßen“ Fachgelehrten versteht, warum er die Grenzen seines Faches überschreiten will und worauf seine „Breitenwirkung“ beruht. Das kann hier natürlich nur kurz und andeutungsweise geschehen.

In einer Fußnote in seinem Buch „Von Athen bis Auschwitz. Betrachtungen zur Lage der Geschichte“ (2002) schreibt Christian Meier: „Die historische Zunft kann zwar ganz gut ohne gesellschaftliches Interesse an ihrer Arbeit leben (sofern die Mittel gesichert sind), doch forscht und lehrt es sich ceteris paribus anders, im Zweifelsfall fruchtbarer, wenn es gegeben ist". Wir sehen: Christian Meier wünscht sich ein gesellschaftliches Interesse an seiner Arbeit als Historiker, um diese Arbeit fruchtbarer betreiben zu können, als dies ohne ein solches Interesse der Fall wäre. Und zwar wird ihm diese Arbeit ganz wesentlich dann fruchtbar, wenn sie es ihm ermöglicht, seine Überzeugung zu verwirklichen, wonach, wie er explizit schreibt, „Historiker eine Funktion in der Öffentlichkeit haben“ sollten; „keineswegs nur für die speziell an Geschichte oder an Teilen davon Interessierten - [...] -, 
sondern auch für die Allgemeinheit; das sei in aller Bescheidenheit festgestellt". Worin besteht die Funktion der Historiker in der Öffentlichkeit? Nach Christian Meier trägt der Historiker die Verantwortung, ,an seiner Zeit wachen Anteil zu nehmen, sich mit seinen Mitteln um deren Erkenntnis zu bemühen". Diese Anteilnahme an seiner Zeit befruchtet ihrerseits die im engeren Sinne fachspezifische Arbeit des Historikers: „Indem er mit den Fragen seiner Zeit im Kopf, die Vergangenheit erforscht und betrachtet, erscheint diese ihm oft in neuem Licht, doch lernt er zugleich die Fragen der eigenen Zeit anders sehen. Was alles helfen die Infragestellungen unserer Zeit zum Beispiel an der Antike entdecken! Was erfährt man auch heute, über die Fragen unserer Zeit zum Beispiel, von der Antike her!"Wie Christian Meier die von ihm übernommene Verantwortung wahrnimmt, „an seiner Zeit wachen Anteil zu nehmen, sich mit seinen Mitteln um deren Erkenntnis zu bemühen“, davon zeugen zahlreiche Veröffentlichungen aus seiner Feder, neben dem schon genannten Buch „Von Athen bis Auschwitz" etwa die Monographien „Die parlamentarische Demokratie“ und „Das Verschwinden der Gegenwart“.

Indem Christian Meier - ich zitiere eine Formulierung von ihm noch einmal - als Historiker an seiner Zeit wachen Anteil nimmt und sich mit seinen Mitteln um deren Erkenntnis bemüht, reiht er sich ein in eine bemerkenswerte und gerade in Deutschland ausgeprägte Tradition. Es ist - gerade auch für den Nichtfachmann - auffällig, daß es immer wieder bedeutende Vertreter des Faches Alte Geschichte gewesen sind, die Verantwortung für die Erkenntnis und auch für die Gestaltung ihrer Zeit übernommen haben. Ich nenne hier Theodor Mommsen, der als Abgeordneter zum Preußischen Landtag und zum Deutschen Reichstag eine aktive politische Rolle gespielt und im sogenannten Antisemitismusstreit gegen Heinrich von Treitschke gekämpft hat. Hier in Göttingen ist in diesem Zusammenhang an Alfred Heuß zu erinnern, dessen aufwühlendes Buch „Versagen und Verhängnis. Vom Ruin deutscher Geschichte und ihres Verständnisses“ wenige Jahre vor der - leider nicht ganz gelungenen - Revolution von 1989 erschienen ist und dazu beigetragen hat, die damals weitverbreitete Überzeugung von der Unerschütterlichkeit der Teilung Deutschlands zu untergraben. In der Gegenwart setzen außer Christian Meier solche Althistoriker wie Wolfgang Schuller und Egon Flaig die Tradition fort, Verantwortung für Erkenntnis und Gestaltung ihrer Zeit zu übernehmen.

Und noch in eine andere von Göttinger Gelehrten mitgeprägte Tradition reiht sich Christian Meier ein. Ich denke hier an seine - auch auf die Gegenwart zielenden - Untersuchungen und Überlegungen zum Problem der politischen Macht, zu der Frage, ob bzw. wieweit ein Politiker, gerade 
auch ein allmächtig scheinender Politiker wie Caesar, Gewalt nicht nur in den Verhältnissen, sondern auch über die Verhältnisse zu erlangen vermag, in denen er agiert. Mit diesem Problem hat sich bereits - auch er als Glied einer langen Traditionskette - der Mitgründer und erste Präsident unserer Akademie, Albrecht von Haller, auseinandergesetzt, dessen 300. Geburtstags Akademie und Universität im vergangenen und in diesem Jahr gedacht haben. In seinen Staatsromanen „Usong - Eine morgenländliche Geschichte“, „Alfred“, „Fabius und Cato, ein Stück der römischen Geschichte“veranschaulicht er „die drei von Montesquieu idealtypisch unterschiedenen Staatsformen" der gemilderten Despotie, der gemäßigten Monarchie sowie der aristokratischen Republik. Ein Zitat aus dem 4. Buch des „Alfred“ mag uns zeigen, daß schon Haller die Ohnmacht des allmächtigen Herrschers erkannt hat. Er läßt den erfahrenen Nordmann Amund zu Alfred sagen: „[... ] ein Despot ist eine umgekehrte Pyramide, ein ungeheueres Gewicht ruhet auf der Spitze, auf einem Punkt; der Hauch eines Westwindes kann den widersinnigen Bau umstürzen“.

Ich komme zum Schluß und fasse zusammen. Christian Meier ist ein Gelehrter, der den beiden Kriterien, denen ein für die Verleihung der Lichtenberg-Medaille vorzuschlagender Kandidat genügen muß, in hohem Maße erfüllt. Wir danken Ihnen, sehr geehrter Herr Meier, dafür, daß Sie die Lichtenberg-Medaille annehmen, und freuen uns auf Ihren Vortrag.

Werner Lehfeldt 


\section{Sieger, Besiegte oder wer schreibt die Geschichte?}

Herr Präsident, meine Damen und Herren,

ich möchte mit einem zweifachen Dank beginnen - für die Ehre, die Sie mir mit der Verleihung der Lichtenberg-Medaille erweisen, aber auch für die Freude, die Sie mir dadurch gemacht haben, daß Sie mir Anlaß boten, mich über mehrere Wochen hin mit dem Patron der Medaille zu unterhalten. Es wird auf ihn noch zurückzukommen sein.

„Der Sieger schreibt die Geschichte“, so kann man es verschiedentlich hören; der Satz geht manch einem leicht von den Lippen. „Der Besiegte schreibt die Geschichte“, so lautet eine These, die Reinhart Koselleck 1988 in einer gelehrten Abhandlung aufgestellt hat. Er knüpft an eine Bemerkung an, welche 1946 der damals frisch besiegte Carl Schmitt gemacht hat. Der berief sich aufTocqueville, den Angehörigen des 1789 besiegten Adels, den 1848 unterlegenen Liberalen (um nur zwei seiner Niederlagen zu nennen). Guizot hatte von ihm gesagt: „c'est un aristocrate vaincu qui accepte sa défaite“. Das sei als Bosheit gemeint gewesen, so Schmitt, erweise aber einen ungewollten Tiefsinn. Denn der Satz lasse „das Arcanum der Größe ahnen [...], das den besiegten Franzosen über alle andern Geschichtsschreiber seines Jahrhunderts erhebt“".

Nach Koselleck legen Sieger ihre Historie kurzfristig an, konzentriert auf jene Taten und Ereignisse, die ihnen den Sieg gebracht haben. Wenn sie sich auf langfristige Trends berufen, führe das leicht zu Deformationen der Vergangenheitssicht. Rückwirkend werde eine Teleologie gezimmert.

„Anders die Besiegten. Deren Primärerfahrung ist zunächst, daß alles anders gekommen ist als geplant oder erhofft. Sie geraten, wenn sie überhaupt methodisch reflektieren, in eine größere Beweisnot“. Daher habe die Hypothese - denn darum handelt es sich - manches für sich, daß gerade aus den einmaligen den Besiegten aufgenötigten Erfahrungsgewinnen Einsichten entspringen, die von längerwährender Dauer und damit größerer Erklärungskraft zeugen. „Mag die Geschichte - kurzfristig - von Siegern gemacht werden, die historischen Erkenntnisgewinne stammen - langfristig - von den Besiegten“.

Koselleck führt eine Reihe von bedeutenden Historikern an, welche Besiegte gewesen seien, angefangen bei Herodot und Thukydides. Es ist 
gleichsam ein statistischer Befund, den er, anknüpfend an seine allgemeinen Erwägungen, vorträgt und an einzelnen illustriert.

Wenn Sieg oder Niederlage wirklich das Fragen, Forschen und Schreiben eines Historikers bestimmen sollen, muß er existentiell davon tangiert sein, sich also mit dem politischen Verband, mit Stand, Klasse oder Kultur, um deren Sieg oder Niederlage es geht, identifizieren. Es muß seine ganz persönliche Sache sein, die auf dem Spiel gestanden hat, wenn er wissen will, warum es so kam, wie es kam. Sieger oder Besiegter ist man zudem, sofern es sich um das Geschick politischer Verbände handelt, in der Regel nur eine Zeitlang. Denn die Verhältnisse wechseln. Bei längerfristigen Prozessen, etwa dem Niedergang eines Adels, mögen sich die Fristen etwas weiter dehnen.

Die Frage, wer die Geschichte - und insbesondere die bessere, an Erkenntnis reichere und (was für Koselleck wichtig ist) methodisch innovative Geschichte - schreibt, Sieger oder Besiegter, kann sich also nur auf bestimmte Werke beziehen, ohnehin nicht auf das Gros der akademischen und der feuilletonistischen Historiographie; auch dann nicht, wenn einer eine Geschichte mit glühendem Herzen geschrieben hat, wie etwa Mommsen die römische. Aber vielleicht ist die Frage, wie und wieweit Sieg oder Niederlage Movens für Geschichtsschreibung sein können, unsinnig? Könnte sie auf den Holzweg führen (falls nämlich diese existentiellen Gegebenheiten allenfalls akzidentiell sind)?

Merkwürdiger-, für mich höchst überraschenderweise hat diese Frage die Historiker der Geschichtsschreibung und die Theoretiker der Geschichtswissenschaft, soweit ich sehen konnte, vor Koselleck nicht interessiert. Wenn die sich mit dem besonderen Engagiertsein von Geschichtsschreibern (oder Historikern überhaupt) befassen, fragen sie nach Parteilichkeit. Hie Welf, hie Waibling sozusagen, klein- oder großdeutsch, konservativ oder fortschrittlich und wie die Positionen alle heißen. Das gehört für Historiker zum Kapitel Objektivität. Von Sieger- oder Besiegtsein ist da keine Rede.

In den Erörterungen über das mögliche persönliche Engagement des Historikers waltet somit das Interesse der Fachleute vor, welche sich fragen, wie man sich zwischen den Kräften, mit denen man es zu tun hat, bewegt (oder bewegen soll). Dazu lassen sich Regeln und Gebote formulieren. Ob einer dagegen den Siegern oder den Besiegten zuzurechnen ist, ist vorgegeben. Vielleicht aber trotzdem von Interesse?

Nur zwei Ausnahmen habe ich gefunden: Graf Boulainvilliers nämlich, der eine wichtige Rolle in den Kämpfen zwischen Monarchie und Adel, spe- 
ziell in der Regentschaft nach dem Tod Ludwigs XIV. spielte, hat bemerkt, es gebe „keine größere Unterscheidung zwischen den Menschen als die zwischen Siegern und Besiegten“. Wie weit er das auf Geschichtsschreibung, speziell auf seine 1727 veröffentlichte „Histoire de l'Ancien Gouvernement de la France" bezog, habe ich nicht feststellen können. In jüngerer Zeit hat Ulrich Raulff, an Kosellek anschließend, in seinem Buch über Marc Bloch die Bedeutung von Sieg oder Niederlage für den Historiker herausgestrichen.

Auch in den neueren Arbeiten, die sich auf die „Kultur der Niederlage“ oder das „Penser la défaite“ beziehen, kommt die Geschichtsschreibung nicht vor. Außerhalb der Geschichtswissenschaft aber ist der Satz „der Sieger schreibt die Geschichte" verbreitet: Carl Schmitt bezeugt, er habe ihn in seiner Jugend, also um 1900, oft gehört; er liege ihm „noch heute im Ohr". In meiner Vorlesung meldete sich mehr als die Hälfte der Studenten, jung wie alt, auf meine Frage, wer den Satz kenne. Er begegnet in Leserbriefen. Schriftlich habe ich ihn sonst nur ganz gelegentlich gefunden. In Brechts Verhör des Lucullus (1936) sagt der Totenrichter: „Immer doch schreibt der Sieger die Geschichte der Besiegten“. Oder George Orwell am 4. Februar 1944: „History is written by the winners“. Er bezog sich auf die beiderseitige Kriegspropaganda und fand: „A nazi and a non-nazi version of the present war would have no resemblance to one another, and which of them finally gets into the history books will be decided not by evidential methods but on the battlefield“. Umstritten ist dagegen, ob Churchill den Satz gebraucht hat. Behauptungen, er habe es, könnten aus einer anderen Äußerung herausgesponnen sein (was immerhin bestätigte, daß der Satz bekannt war). Jene Äußerung ist übrigens sehr schön. Churchill habe in den 1930er Jahren Premierminister Baldwin einmal entgegengehalten: „That he was confident history would find Baldwin wrong - because I shall write that history". Hier hätte also nicht der Sieger die Geschichte geschrieben, sondern der Unterlegene hätte als Geschichtsschreiber nachträglich über den Sieger gesiegt.

Eine andere Äußerung, die die Redensart indirekt bezeugen könnte, stammt von Jacob Burckhardt, der Silvester 1872 befürchtete, „die ganze Weltgeschichte von Adam an“ werde „siegesdeutsch angestrichen und auf 1870 bis 1871 orientiert sein. Den nächsten Krieg gewinnt man ohnehin gewiß auch noch".

1991 hat Winfried Martini ein Buch unter dem Titel „Der Sieger schreibt die Geschichte“ veröffentlicht. Es geißelt die Besiegten-Mentalität, die Unterwürfigkeit der Deutschen nach 1945, die eben dazu geführt habe, daß die Geschichte im Sinne der Sieger verstanden wurde. 
Zuvor hat Nietzsche die Sache einmal, aber mit andern Worten, festgestellt: „Alle Geschichte ist bis jetzt vom Standpunkt des Erfolgs, und zwar mit der Annahme einer Vernunft im Erfolge geschrieben“. Erfahrung jeweiliger Gegenwart pflegt dem entgegenzukommen. „Ist es doch sicherer, auch angenehmer für das Gemüt, im Lager der Sieger zu sein als bei den Besiegten; kennen wir doch alle die Versuchung, dem Sieger auch das historische Recht beizumessen“. So Golo Mann, übrigens zur Lage in Deutschland nach dem Sieg Hitlers. Worauf das in der Historiographie hinausläuft, macht Nietzsche deutlich, wenn er von „Geschichte als dem Hohn der Sieger" spricht. Schließlich gibt es das berühmte Benjamin-Zitat aus dessen siebter geschichtsphilosophischer These: „In wen fühlt sich der Geschichtsschreiber des Historismus ein? Die Antwort lautet unweigerlich in den Sieger. Die jeweils Herrschenden sind aber die Erben aller, die je gesiegt haben".

Wie weit Sieger selbst darauf pochen, daß sie es seien, die die Geschichte schreiben, und Reklamationen der Besiegten damit abschmettern, ob der Satz also gleichsam die historiographische Seite des vae victis darstellen kann, weiß ich nicht. Carl Schmitt vermutet es. Jedenfalls kann sich das Ressentiment der Besiegten darin äußern. Siegergeschichte - das klingt wie Siegerjustiz. Es liegt ein Vorwurf darin; wie bei Benjamin.

Immerhin ist eines richtig: Es gibt die Sieger, die Wert darauf legen, daß Geschichte in ihrem Sinne geschrieben wird. Sie können ihre Historiker fördern und dirigieren; Stefan Heym hat das in seinem König-David-Report sehr schön durchgespielt. Sie können Besiegte davon abhalten, ja abschrecken, Geschichte in deren Sinne zu schreiben (oder falls sie es doch tun, sie verfolgen und ihre Werke verbrennen). Und es kommen ihnen die Neigungen all derer zugute, die sich den Vorgaben der Stärkeren, der Erfolgreichen fügen. Dies alles kann natürlich von Historikern festgestellt werden. Schon im vierten Jahrhundert hat der christliche Historiker Orosius von den ,iudicia victoris“, den Sprachregelungen des Siegers gesprochen, die die Geschichtsauffassung bestimmen. Der Sieger kontrolliert zudem den Zugang zu den Archiven. Und vielen Besiegten wird eben mit ihrer Niederlage die Möglichkeit, ihre Geschichte zu schreiben, abgeschnitten, etwa Galliern, Spaniern und Germanen im Römischen Reich. Wenn es sich bei Griechen und Juden anders verhielt, so deswegen, weil sie längst ihre eigenen Formen von Geschichtsschreibung ausgeprägt hatten. Insofern spricht also wirklich einiges dafür, daß, wenn auch keineswegs immer, Geschichte im Sinne des Siegers geschrieben wird. Indes nicht unbedingt auch dafür, $\mathrm{da}$ es gute Geschichte ist. Die historischen Partien des Alten Testaments, 
weithin Besiegtengeschichte, stellen einen Sonderfall dar, der hier beiseite bleiben mag.

Was soll man von diesem Befund halten? Ein Gemeinspruch und eine These Reinhart Kosellecks, immerhin eines der bedeutendsten Historiker Nachkriegsdeutschlands. Wenn sie richtig ist, ist es eine Erkenntnis, die nahezu zweieinhalb Jahrtausende seit der Erfindung der Historie und gut zweihundert Jahre seit der Begründung der neuzeitlichen Geschichtswissenschaft darauf hat warten müssen, gewonnen zu werden - falls ich nichts übersehen habe.

Ich möchte der Sache ein Stück weit nachgehen. Zunächst und vor allem, indem ich zwei wichtige Beispiele vorstelle, die in mein engeres Fach gehören, nämlich Herodot und Thukydides. Daran anschließend möchte ich einige Fragen aufwerfen, denen eine gewisse Aktualität zukommt. Sie betreffen die Besiegten von 1945, die Deutschen also insgesamt, und die von 1989, die Deutschen aus der DDR.

Herodot, der nach Koselleck „nicht zu den völlig Besiegten“ zählte, aber jedenfalls zu denen, die sich durch die Beschleunigung der Zeit infrage gestellt sahen, gilt mit gutem Grund als „Vater der Historie“. Er wollte wissen, wie Europa und Asien in Konflikt gerieten. Wie es nämlich dazu kam, daß ganz Asien (nach damaligen Begriffen) von den Persern unterworfen wurde und wie sodann der Krieg der Perser gegen die Griechen ausbrach, in dem die Griechen erstaunlicherweise siegten. Ein ungeheures Geschehen, weit abseits von allem Gewohnten: Eine zusammenhängende Welt war in zwei zerbrochen, Ost und West. Und ein paar kleine Griechenstädte hatten ein Weltreich besiegt; ein David einen Goliath.

Herodot hatte umfangreiche Untersuchungen in verschiedenen Ländern angestellt. Das Ergebnis trug er, und das ist entscheidend, in Form einer Geschichte vor. Er kannte den Begriff Geschichte nicht, aber er schrieb sie. Er machte nämlich etwas, was heute das Selbstverständlichste (und gelegentlich auch das Langweiligste) von der Welt ist: Zeichnete verschiedene Abläufe nach, und zwar über zwei bis drei Generationen, bis sie sich schließlich zu einem einzigen vereinten, dem des Perserkriegs. Ganz einfach, so scheint es uns: Da entsteht Streit, Mächte prallen aufeinander, Schlachten werden geschlagen. Über ihren Ausgang entscheidet nicht nur die Stärke der Armeen, ihre Führung, ihre Tapferkeit, sondern auch Geographie, Wind und Wetter, Überraschungsmomente; Zufälle (wie wir das einstufen können). Am Ende wird der Besiegte dem Perserreich einverleibt - oder auch nicht, was eben bei den Griechen der Fall war. 
Diese Methode - nennen wir sie kurz die ereignisgeschichtliche - war nicht in jeder Hinsicht neu. Denn daß man sich wichtige Ereignisse nachträglich vor Augen führte, indem man das Mit- und Gegeneinanderwirken der Beteiligten samt zufälligen Umständen nachzeichnete, muß längst üblich gewesen sein, für die Griechen wie für die Angehörigen der orientalischen Hochkulturen. Keine Schlacht, keine diplomatische Aktion konnte sonst verstanden, keine Manöverkritik geübt werden. Aber daß einer ganze generationenübergreifende Abläufe auf diese Weise einfach in der Abfolge oft zufälligen Sich-Verschlingens einer Unzahl von Handlungen bestehen ließ, dafür kennen wir - um von einer möglichen entfernten Parallele im Alten Testament abzusehen - zuvor kein Beispiel. Das scheint eine völlige Neuheit gewesen zu sein.

Denn das übliche Verständnis des Ausgangs längerfristiger Abläufe erfolgte, auch bei den Griechen, mit Hilfe von Vorbestimmungen, mit Kategorien von Götterwillen und Schicksal. Wobei Gerechtigkeitsvorstellungen mitsprachen. Jeweils bezog man sich auf ein Geschick, das einzelnen Subjekten, großen Männern etwa, Dynastien oder Reichen, zugemessen war. Wenn ein Reich unterging, war das die Strafe für frühere Vergehen. Das Ende einer Dynastie erklärte man sich gern damit, daß ihre Zeit abgelaufen war. Mit derlei Annahmen kann man sich das Studium längerer Abläufe ersparen. Übrigens ließen sich ähnlich auch kurzfristige Ereignisse verstehen: Wenn die assyrische Armee Israel besiegte, konnten die Israeliten den Sinn darin sehen, daß Jahwe sein Volk strafen wollte - wie wenn die Assyrer aus eigenem Interesse gar nichts im Schilde geführt hätten. Nach Aischylos war die Niederlage der Perser dadurch bedingt, daß der Perserkönig Xerxes mehrfach gegen den Willen der Götter verstieß und daß die auch nicht wollten, daß ein einziger Mann Asien und Europa beherrschte.

Anders Herodot. Er berichtet zwar auch von Deutungen irdischen Geschehens aufgrund von Götterwillen (wie er sich etwa in Zeichen und Orakeln greifen ließ). Seine Gewährsmänner werden sie ihm in ihren Erzählungen mitgeliefert haben. Und er neigt offensichtlich dazu, je folgenreicher die Ereignisse, um so mehr mit einem tiefer bedingten Sinn, einer tieferen Gerechtigkeit zu rechnen. Und sei es, daß er bei einer Niederlage erklärt, dem Unterlegenen „sollte es schlecht ergehen“. Auch Herodot kennt die Version, Götter und Heroen hätten nicht gewollt, daß einer Asien und Europa beherrsche. Der führende athenische Feldherr Themistokles, der Sieger von Salamis, habe das geäußert.

Aber - solche Annahmen, solche Sinnvermutungen hindern Herodot nicht daran, die Ereignisgeschichte auf längere Strecken möglichst genau 
empirisch zu ermitteln und wiederzugeben. Letztlich ist es für ihn ein Gebot, aufzuweisen, was er über die Abläufe in Erfahrung gebracht hat: Die empirisch ermittelte Ereignisgeschichte.

Von heute her ist kaum zu ermessen, was das, in der Konsequenz, bedeutete: $\mathrm{Da}$ große, die Welt verändernde Abläufe, aufs ganze gesehen, Menschensache, also dem Handeln verschiedener Subjekte und nicht zuletzt den Zufällen anheimgegeben sein sollten. Wie wenn weiter gar nichts dabei gewesen wäre. Götterwille hin, Autonomie menschlichen Handelns her: Man wollte sich empirisch dieser Abfolge von Interaktionen vergewissern; auch auf längerfristige Geschehenskomplexe den Modus des Verstehens durch Nachvollzug anwenden.

Wie Herodot dazu kam? Wir wissen, daß er sich den gegen Ende des sechsten Jahrhunderts entwickelten Methoden der jonischen Feldforschung verpflichtet fühlte. Man wollte die Welt aufnehmen, möglichst umfassend (im Rahmen bescheidener Möglichkeiten), zunächst geographisch und ethnographisch, auch aus praktischen Interessen. Herodot hatte daran teil, übertrug den Anspruch aber eben zugleich auf Abläufe: Er wollte - und die Leser (respektive Hörer seiner Vorträge) sollten - wissen, was sich zugetragen hatte, genauer: was darüber zu ermitteln war. Anders konnte er dem großen, viele Völker umfassenden Geschehen samt seiner Vorgeschichte nicht beikommen. Schon weil das Material organisiert werden mußte, legte es sich nahe, die Bildung des Perserreichs und den Perserkrieg historisch darzustellen und letzten Endes zu verstehen.

Diese damals so neue Historie aber stammt eindeutig von einem Angehörigen des Siegervolks. Er verurteilt die Athener zwar dafür, daß sie die Perser herausgefordert hatten. Daß sie aber ihre Freiheit verteidigten, war ganz in seinem Sinne. Wie weit er sich in Frage gestellt sah, möge dahinstehen. Wenn er, wo es sich anbot, mit herkömmlichen Kategorien urteilte, so blieb er dabei jedenfalls nicht stehen. Eines ist allerdings unstrittig: Dieser Historiker von der Siegerseite hat mit denen der Besiegten, zumindest mit denen unter ihnen, die wirklich Format haben, gemein, daß ihm der Ausgang des Krieges ein großes Rätsel war. Alles andere als selbstverständlich; ganz anders, als man hätte denken sollen. Insofern war er ein untypischer Sieger.

Etwa eine Generation jünger als Herodot war Thukydides. Der eine war am Ende der Perserkriege, die er darstellte (479 v. Chr.), ein Kind; der andere zu Beginn seines, des Peloponnesischen Kriegs (431) erwachsen. Er hat von Anfang an die Absicht gehabt, dessen Geschichte zu erzählen. Alle Wahrscheinlichkeit spricht dafür, daß er zunächst mit einem Sieg seiner Vaterstadt Athen rechnete. Und mehrere Jahre lang sah es ja auch so aus, als ob es dazu kommen würde. So hat er zunächst als präsumtiver Sieger 
geschrieben. Am Ende aber war er nicht nur als Athener, sondern auch in seinen Erwartungen besiegt.

Knapp fünfzig Jahre lagen zwischen Perser- und Peloponnesischem Krieg. Es war die Glanzzeit des klassischen Athen. Nachdem sie die Perser zurückgeschlagen hatten, waren die Griechen zu einem begrenzten Gegenangriff angetreten, um die Griechenstädte an der kleinasiatischen Küste zu befreien. Das Kriegsbündnis wurde ausgeweitet. Athen, die an Bürgern reichste Stadt, übernahm die Führung. Es geriet dadurch in eine Spannung zwischen Sein und Sollen, die ihresgleichen sucht: Fast über Nacht wurde es vom Kanton zur Großmacht. Das konnte nur gutgehen bei Anspannung aller Kräfte und bei einem hohen Maß an Rücksichtslosigkeit. Die Stadt mußte weiträumig und längerfristig denken und Politik machen lernen, berechnend, planend - lauter Dinge, auf die keiner vorbereitet war. Mit der Kluft zwischen Kanton und Großmachtfunktion war die zwischen Hergebrachtem und Angebrachtem verquickt. Kurz: Athen mußte aus der gewohnten Welt der mehr oder weniger mit sich selbst beschäftigten Poleis ausbrechen. Es mußte große Dynamik entfalten. Widerstände veranlaßten es, die eigene Macht immer weiter auszudehnen. Die Kraft, die es dazu brauchte, bezog es aus einer Art Dauermobilisierung seiner Bürgerschaft. Und die genoß ihre Rolle.

Viele der Verbündeten jedoch hatten bald genug von der aufreibenden (und kostspieligen), ungeliebten Aktivität, die daraus resultierte. Da die Athener sie zwangen, bei der Stange zu bleiben, verwandelte sich das Bündnis in eine Herrschaft, eine Tyrannis über einen Großteil der Poliswelt. Thukydides läßt Perikles, Athens führenden Staatsmann, erklären, eine Tyrannis zu begründen möge ungerecht sein, sie loszulassen jedoch sei gefährlich. Wohl war sie so gut organisiert und mit militärischer Macht unterfangen, daß sie sich behaupten ließ. Aber der Haß war groß. Wenn der Rivale Athens, Sparta, samt seinen Bundesgenossen gegen die Stadt zu Felde zog, mochte die ganze Herrschaft auf dem Spiel stehen.

Als der Krieg drohte, fand Perikles, man müsse ihn auf sich nehmen. Dürfe keine Schwäche zeigen. Und es sei auch durchaus möglich, zu siegen und sich auf Dauer zu sichern. Alles komme darauf an, unmißverständlich zu beweisen, daß Athen unschlagbar sei. Darauf beruhte sein Kriegsplan: Die Spartaner waren zu Land überlegen. Also dürfe man es dort nicht zur Schlacht kommen lassen, sondern müsse sich hinter den Mauern verschanzen. Man dürfe auch keine Eroberungen machen, möglichst keine Risiken eingehen. Vielmehr müsse man von der See her, welche Athen beherrschte, ständig in das Land des Feindes einfallen - bis er klein beigab. Ein Ermattungskrieg mußte es also sein. 
Dieser Plan hat Thukydides überzeugt. Das wird in expliziten Äußerungen ganz deutlich. Er beruft sich darauf, daß die Mittel Athens so reichlich gewesen seien, daß man eine lange Reihe von Fehlern, Abweichungen vom Plan habe machen können - und trotzdem der wachsenden Übermacht der Feinde über viele Jahre standhalten. Warum aber ging der Krieg gleichwohl verloren?

Weiteste Strecken seines Werks dienen der Darstellung der politischmilitärischen Abläufe. Thukydides übernimmt von Herodot das Modell der Ereignisgeschichte. Er wendet es nur in einer viel weitergehenden methodischen Bewußtheit und Konsequenz an, sowohl in der kritischen Ermittlung der Sachverhalte wie in der Organisation ihrer Wiedergabe. Darin besteht jenseits von Sieg und Niederlage sein Ruhm. Sorgfältig sucht er nicht nur die jeweiligen Absichten und Erwartungen der Handelnden herauszuarbeiten, sondern auch, wie mächtig ein Faktor jeweils dazwischenkommen konnte, den er unter anderm mit einem wohl von ihm selbst gebildeten bemerkenswerten Wort (im Maskulinum, nicht im Neutrum!) ho parálogos nennt, den „Denkwidrigen“, den Unberechenbaren. „Nie läuft ein Krieg nach festgelegtem Plan; aus sich selbst heraus erfindet er immer Neues für jede neue Lage“.

Und Thukydides' Geschichte vollzieht sich zu hundert Prozent unter den Menschen. Götter und Vorzeichen spielen nur insoweit eine Rolle, als der Glaube an sie das Handeln der Menschen beeinflussen kann. So gehorcht er den gleichen Geboten, wie sie damals in der Schule des Hippokrates entwickelt wurden: Die (Krankheits)Abläufe sind genau zu registrieren, Krankheitsursachen wie Heilmittel sind im profanen Bereich zu suchen, frei von Religion und Magie.

In den Abläufen aber, in den ereignisgeschichtlichen Verwicklungen (mit all ihren Zufällen) liegt nicht alles zutage. Schon für den Anfang des Krieges reicht es nicht, dessen Anlässe nachzuzeichnen. Viel wichtiger ist der „wahrste Grund“. Thukydides übernimmt hier eine Unterscheidung des Hippokrates, der die „zum Vorschein kommende Ursache“ (próphasis) einer Krankheit klar von der Abfolge der Symptome unterscheidet. Ursache des Kriegs sei die Furcht der Spartaner vor der wachsenden Macht Athens gewesen.

Aber wie steht es mit der Niederlage? Gibt es auch da einen „wahrsten Grund"? Direkt benannt wird keiner. Wohl stellt Thukydides fest, daß die Athener Perikles' Kriegsplan nach dessen Tod nicht eingehalten haben. Immer weiter haben sie ausgegriffen. Die Politiker haben sich selbstsüchtigen Ränken und Streitigkeiten hingegeben. Keiner von ihnen hatte die Autorität des Perikles, jeder mußte allererst um die eigene Macht ringen 
(und Konzessionen machen), außerdem hatten sie private Interessen über die der Stadt gestellt. Was die Stadt teuer zu stehen kam. Doch dienen ihm diese Erwägungen nur dazu, zu zeigen, wie gut Perikles Athens Macht berechnet hatte. Daß die späteren Politiker - oder gar die Demokratie die Niederlage verschuldet hätten, sagt Thukydides nicht. Sie sind gewiß nicht ohne Schuld an ihr. Aber die Sache ist komplizierter.

Denn es walten da gewisse Zwänge, unter denen Athens Politik steht, und aus denen erwächst eine gewisse Tendenz zu immer weiterem Ausgreifen. Die Menschen sind, ist er überzeugt, ihrer Natur nach immer gleich. Das heißt, bestimmte Antriebe sind ihnen allen gemein. Es sind vor allem Ehrliebe, Mehr-haben-Wollen und Furcht. Wie sie wirken, hängt von den Lagen $a b$, in denen die Menschen sich befinden, sowie von den Eigenarten, die die Bürgerschaften ausbilden. Für die Athener hieß das zunächst, daß sie ihre Herrschaft behaupten mußten, schon aus Furcht vor der Rache der von ihnen Beherrschten. Insofern waren sie nicht frei, sondern getrieben. Thukydides läßt sie das selbst immer wieder betonen.

Die Weise aber, in der sie ihre Herrschaft behaupteten, führte sie dazu, immer stärker zu werden. Thukydides spricht von den prágmata, den Handlungskonstellationen nach den Perserkriegen, aufgrund derer sie dazu kamen. Sie waren allen andern überlegen, schon weil sie ihnen dank Schnelligkeit und Wagemut weit voraus waren. Aus den Erfolgen schöpften sie Zuversicht, die ihnen zu neuen Erfolgen verhalf. Diese Tendenz ist besonders an einigen Situationen im Laufe des Krieges zu greifen. Da machten sie zum Beispiel einen der trügerischsten Faktoren, die Hoffnung, zur Basis ihrer Erwartungen. Einmal heißt es, „im Genuß ihrer glücklichen Lage“ hätten sie „beansprucht, daß ihnen nichts in den Weg trete, sondern daß sie das Mögliche in gleicher Weise wie das kaum Mögliche mit großer und ebenso mit dürftigerer Rüstung erreichten ". Man hatte wenig Aussicht, wie er einmal sagen läßt, die Athener „gegen ihre Eigenart" zu überzeugen, wenn man sie ermahnen wollte, was sie besitzen, zu bewahren, statt mit Einsatz dessen, was ihnen zu Gebote steht, um einen Gewinn, der im Dunkel der Zukunft liegt, ein Risiko zu übernehmen. So griff eins ins andere, meist ging es gut.

Als Perikles' Neffe Alkibiades die sizilische Expedition, die zur Peripetie des Krieges werden sollte, betreibt, läßt Thukydides sie ihn unter anderm damit begründen, daß die Stadt ihre Herrschaft immer weiter ausdehnen müsse. Täte sie es, so bleibe sie ihrer Art und ihrem Brauch treu. Im Kampf gewinne sie neue Erfahrung und Wehrhaftigkeit. Erobere sie Sizilien, so könne sie ganz Griechenland beherrschen. Verharre sie dagegen bei dem, 
was sie habe, so werde sie vergreisen und bald der Herrschaft anderer unterliegen.

Perikles' Kriegsplan widersprach danach dem Wesen Athens. Und vielleicht tat er es wirklich, indem er meinte, man könne sich auf die Verteidigung dessen beschränken, was die Stadt gewonnen hatte. Thukydides sagt nichts darüber, außer daß er die starke Führung durch diesen Mann beschwört. Allein, konnte Athen saturiert sein? Bewegte es sich nicht in jener eigentümlichen Art von Strömung, welche entsteht, wenn eine Menschengruppe durch überraschende Serien von Erfolgen daran gewöhnt wird, ihre Kräfte bis zum äußersten anzuspannen? Da muß sie über längere Zeit leisten, was eigentlich über ihre Kapazität hinausreicht. Vielleicht will sie gar nicht unbedingt voranschreiten, aber sie kann nicht stehenbleiben. Die Zuversicht, die aus ihren Erfolgen wächst, reißt sie zu Neuem hin. Warner haben da schlechte Karten. Das „Mehr-haben-Wollen“ wird zur Unersättlichkeit. Thukydides selbst trägt in der sogenannten Pathologie des Krieges vor, wie ein entfesseltes Machtstreben die Beteiligten immer weiter treibt, bis tief in die Perversion hinein.

Dieser Prozeß nun der gegenseitigen Überbietung von Erfolg und Erwartung, dessen Mechanismus bei Thukydides aufscheint, hat Athens Aufstieg so befördert, wie er schließlich, wohl notwendig, zum Verlust des Krieges führte. Der Versuch, Sizilien zu erobern, markiert den Umschlag.

Wohl erklärt Thukydides ausdrücklich, daß die Expedition dorthin, was das Militärische anging, hätte Erfolg haben können; obzwar das Risiko hoch gewesen sei. Es seien vor allem innenpolitisch bedingte Fehler, eben die Umstände der nachperikleischen Demokratie, gewesen, die das Scheitern bedingten. So hat es sich auf der Ebene der Ereignisgeschichte dargestellt.

Andererseits konnte Athen seine Herrschaft nicht unbegrenzt weiter ausdehnen. Alkibiades hatte schon ein Auge auf Karthago geworfen. Wäre die Eroberung Siziliens geglückt, hätte also vielleicht ein Zug gegen Karthago die Wende gebracht. Ein Zurückstecken oder ein einfaches Auslaufen der Dynamik Athens - etwa durch einen dauerhaften Frieden - war kaum zu erwarten. Dazu war die Erbitterung zu groß, mit der schließlich um die Erhaltung oder Beseitigung der attischen Herrschaft gekämpft wurde. Dazu hätten Athens Kräfte erst gänzlich erschöpft werden müssen.

$\mathrm{Zu}$ fragen ist, wie sich die Strömung des immer weiteren Ausgreifens jeweils auf der politisch-militärischen Ereignisebene geltend machte; in jenem Bereich, in dem sich Kriege vollziehen, wo Menschen ihre Pläne verfolgen, wo im Aufeinanderwirken der verschiedenen Kräfte unter Beimischung von Zufällen die Entscheidungen fallen. 
Dazu erfährt man bei Thukydides nichts. Ereignisgeschichtlich hätte es, wie er es darstellt, stets anders kommen können, als es kam. Auch bei den Beratungen in Sparta, die den Ausgangspunkt des Kriegs darstellten. Der „wahrste Grund“ des Krieges mußte sich dementsprechend wohl irgendwann, aber nicht unbedingt 431 geltend machen, ebenso, wie die sizilische Expedition hätte Erfolg haben können.

Auf der Ereignisebene herrschte also von Situation zu Situation viel Freiheit und Zufall. Das heißt, tiefere Ursachen oder längerfristige Tendenzen - wie übrigens auch Strukturbedingungen, das Vorhandensein oder Fehlen von Mitteln - setzten sich nur mit gleichsam statistischer Wahrscheinlichkeit durch, wann immer es soweit war. Wir stehen hier vor einem eigentümlichen Problem aller Geschichtsschreibung. Das Bedürfnis, längerfristige Abläufe zu verstehen, kann sich selten mit der Rekonstruktion der Ereignisgeschichte ganz zufriedengeben. Herodot hatte sich mit verschiedenen Sinnvermutungen beholfen, um streckenweise tiefere Zusammenhänge „festzustellen“. Thukydides entdeckte den Prozeß der Dynamik Athens, die schließlich umschlug. Wie sie sich im einzelnen zur Geltung brachte, mußte zunächst offen bleiben. Soweit Thukydides' Erkenntnismöglichkeiten reichten, stand eines neben dem andern. Die Ereignisgeschichte ließ sich empirisch, gleichsam aus der Nähe nachzeichnen, der Prozeß aus der Distanz beobachten.

Aber an einer Stelle, eben bei der sizilischen Expedition, brach sich gleichsam die Dynamik des immer weiteren Ausgreifens Bahn innerhalb der Ereignisgeschichte, indem sie - wenn auch nicht notwendig, vielmehr dank des Alkibiades - zur Katastrophe führte. Thukydides hat das höchst eindrücklich inszeniert, wobei er in eigentümlicher Weise eine weitere Deutungsressource ins Feld führte.

Er hat nämlich dem Bericht über die sizilische Expedition den sogenannten Melierdialog vorangestellt. Kurz vorher hatte Athen beschlossen, die Insel Melos zu unterwerfen. Da sie sich zur Wehr setzte, wurde die Stadt belagert, am Ende wurden die Männer hingemordet, Frauen und Kinder in die Sklaverei verkauft. Diese Gelegenheit nun nutzt Thukydides, um einen erfundenen Dialog einzuschieben. Er läßt die Athener ihre Forderungen mit brutaler Offenheit vorbringen. Die Melier berufen sich auf ihre Freiheit, auf das „gemeinsame Gut" von Gehörig- und Gerechtigkeit. Sie erhoffen Unterstützung durch Sparta. Und sie beziehen sich auf die Götter. Dies alles weisen die Athener voller Hohn zurück. Allzu harmlos und altmodisch seien die Melier; haben offenbar keine Ahnung, wie es im Umgang mit einer modernen Großmacht zugeht. Sie reden von Gerechtigkeit, wo es sich allein 
um Nützlichkeit handeln kann - und darum, das Mögliche zu tun oder zu erreichen.

Denn zwischen Mächtigen und Schwachen walte das Recht des Stärkeren: Es gebe - überall zu beobachten - einen Zwang der Natur, daß man beherrscht, worüber man Gewalt haben kann. Das gilt, sagen sie, offensichtlich unter den Menschen, aber vermutlich auch unter den Göttern. Auf das Angebot der Melier, ihre Freunde zu sein (freilich bei Wahrung der Neutralität), entgegnen sie: Viel lieber als die Freundschaft der Melier sei ihnen deren Feindschaft. „Denn der Haß ist ein Zeichen unserer Macht für die, die wir beherrschen“. Folglich wollen die Athener gehaßt werden. Man muß dazuhalten, daß Thukydides seine Redner gern sagen läßt, was sie praktischerweise nicht gesagt, was sie aber gemeint oder geplant haben müssen oder zumindest: worauf das hinauslief, was sie meinten oder wollten. Perikles hatte den $\mathrm{Haß}$ nur als zwangsläufige Folge der Herrschaft hingestellt. Jetzt wird seine Erzeugung geradezu zum Herrschaftsprinzip. Thukydides läßt die Melier darauf hinweisen, daß mit der Erweiterung des attischen Machtbereichs auch der $\mathrm{Haß}$ der Unterworfenen wächst. Er hatte zuvor schon den Umgang Athens mit seinen „Bundesgenossen“ kritisiert.

Wie er es liebt, verschiedene Argumente und Standpunkte gegeneinanderzusetzen, ohne Stellung zu nehmen, überläßt er es dem Leser auch hier, sei es den Athenern, sei es den Meliern zuzustimmen. So, wie die Athener argumentieren, muß es auch damals einem breiten Kreis unter den Griechen - Thukydides vermutlich eingeschlossen - als ungeheuerliche, empörende Hybris, als Überschreiten der Grenzen des Erlaubten erschienen sein. Man könnte es auch Hochmut vor dem Fall nennen.

Gemäß dem Arrangement des Thukydides ist von diesem Fall auch gleich im Anschluß die Rede: In Sizilien ereignet sich eine entsetzliche Katastrophe. Und er rahmt den Bericht darüber durch ungewöhnlich eindrucksvolle Schilderungen ein. Eine Riesenflotte, wie sie noch nie auf so weite Fahrt gegangen war, ist aufgestellt. Alle Mühe hat man darauf verwandt, sie aufs prächtigste auszustatten. Ein Schiffsherr suchte den andern zu übertreffen. Am Tag der Abfahrt strömt ganz Athen zum Hafen, viele, um Söhne, Freunde, Verwandte zu den Schiffen zu geleiten. Im Moment des Abschieds tauchen sie in ein Wechselbad von verwegener Hoffnung und Angst. Endlich ertönt eine Trompete. In das Schweigen der ungeheuren Menge spricht ein Herold für alle das Gebet. Auf den Schiffen wird den Göttern aus goldenen und silbernen Bechern geopfert. Die Flotte fährt in Linie aus, dann drehen die Schiffe, um in allem Übermut bis Ägina um die Wette zu fahren.

Zwei Jahre darauf, als die Athener, besiegt, ihr Lager bei Syrakus aufgeben müssen, sieht man sie gesenkten Hauptes abrücken. Die Toten müs- 
sen unbegraben zurückbleiben; wer einen der Seinen unter ihnen erblickt, ist bleich vor Kummer und Beklemmung. Schrecklicher noch sind die Verwundeten und Kranken, welche flehen, man solle sie mitnehmen, teilweise hinter den Abziehenden herhinken, schließlich mit lauten Beschwörungen und Wehgeschrei zurückbleiben. Unter Tränen schleichen sich die Reste der Armee davon - um am Ende, soweit sie überleben, in Gefangenschaft zu geraten, in Steinbrüchen aufs übelste von Hitze und der kalten Nacht geplagt zu werden, siebzig Tage lang. Hunger und Durst, viele sterben, man stapelt die Toten, weil es nicht anders geht, in der Enge des Lagers.

Thukydides nennt diese Niederlage das bedeutendste Ereignis von allen in diesem Krieg, vielleicht von allen, welche aus griechischer Überlieferung bekannt sind. Er türmt die Worte geradezu: katà móvta - auf der ganzen

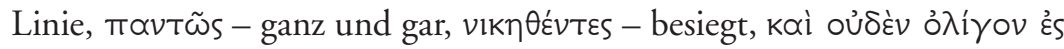

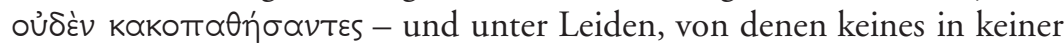
Hinsicht etwa klein war, $\pi \alpha v \omega \lambda \varepsilon \varepsilon \theta$ pía tò $\lambda \varepsilon \gamma o ́ \mu \varepsilon v o v$ - mit Stumpf und Stiel, wie man sagt, gehen Fußvolk und Flotte unter, „und nichts, was nicht vertilgt wurde. Wenige von vielen kehrten heim“.

Damit kommt der Prozeß steten Ausgreifens an sein Ende. Es fällt kein Wort darüber, daß Athens so maßlose, zynische Politik, wie sie im Melierdialog zum Ausdruck kam, den Kriegsverlauf negativ beeinflußt hätte. Nicht der Haß, sondern die Niederlage in Sizilien führt in der Folge zum Zusammenbruch der Herrschaft. Denn die Furcht hielt die Bundesgenossen zunächst gefangen. Nur als (und weil) Sparta gegenüber dem tiefgeschwächten Athen sich als stark erweist, wagen sie es abzufallen.

Trotzdem scheint es seinen guten Sinn zu haben, daß Thukydides durch sein Arrangement die äußerste Kulmination attischen Machtstrebens auf die, so wie er es darstellt, Kulmination des - aller Sittlichkeit hohnsprechenden - attischen Herrschaftsgebarens unmittelbar hat folgen lassen. Irgendwie scheint sich da doch ein Zusammenhang aufzutun; wenn nicht in der Auswirkung, so doch im Ausgangspunkt. Man kann es verschieden deuten. Wird da neben der Macht- und Ereignisrechnung noch eine zweite aufgemacht? Ist die mutwillige Haßerzeugung ein Symptom dafür, wie weit es mit und aufgrund der attischen Dynamik gekommen ist? So daß die sizilische Expedition und das Auftreten in Melos nur verschiedene Produkte und Ausdrücke derselben Perversion waren, die diese Dynamik am Ende erreicht hatte? Oder soll angedeutet werden, daß eine Stadt, die unerträglich geworden war, sich letzten Endes doch nicht behaupten konnte? Schließlich ging es nicht um irgendeinen Krieg oder irgendein Gefecht - da mag dergleichen egal sein -, sondern um Bewahrung oder Verlust der Größe der unter den Griechen herrschenden Macht. Konnte es da gleichgültig sein, 
daß sie alle Regeln des Zusammenlebens der Poleis zu verachten, das „gemeinsame Gute" mit Füßen zu treten sich angewöhnt hatte? Ja vielleicht gar: Durfte diese Stadt gewinnen?

Was sich nicht im Sinne der strengen Methodik des Thukydides sichern ließ, wurde durch künstlerische Mittel - Rede, Dialog, Arrangement - zur Sprache gebracht. Von verschiedenen Seiten und auf verschiedene Weise kommt er also dazu, daß es bei der Niederlage Athens nur allzu sehr mit rechten Dingen zugegangen war.

$\mathrm{Ob}$ es ihm bewußt wurde, daß es der gleiche Prozeß der fulminanten athenischen Macht- und Selbstentfaltung war, dem zunächst seine eigenen zuversichtlichen Erwartungen entsprangen und der schließlich auf den Verlust des Krieges hindrängte? Jedenfalls hat Thukydides sich nicht gescheut, sich mit seinen fehlgelaufenen Erwartungen auseinanderzusetzen, hat seine Fragen immer weiter getrieben in großer Offenheit und Freiheit, um die Geschichte, die zur Niederlage seiner Vaterstadt führte, zu verstehen. Hat Erkenntnis an die Stelle der Pflege liebgewordener Abwehrmechanismen gesetzt. Hat einen methodischen Anspruch entwickelt, der es verbot, irgendeine - und sei es allenfalls zu vermutende - unangenehme Wahrheit zu unterdrücken.

So konnte er nicht nur Politik und Krieg (wie Menschenleben) erstaunlich gut begreifen, sondern auch ganz neue, so bald nicht wieder eingeholte, Methoden des Begreifens historischer Abläufe und Zusammenhänge entwickeln, aus der Niederlage einen Sieg der Erkenntnis machen (der wie so viele andere Produkte seines Jahrhunderts bis heute auszustrahlen vermag). Was, wenn nicht die Herausforderung durch die Lage des Besiegten soll ihn dazu instandgesetzt haben? Daß einer auf der Seite der Sieger, ein Korinther etwa, ähnliches vermocht hätte, darf doch wohl bezweifelt werden. Die Antwort war ein Werk, von dem Hegel sagen konnte, es bedeute den absoluten Gewinn, den die Menschheit vom Peloponnesischen Krieg habe.

Wie so oft ist die Verarbeitung der Niederlage auch bei Thukydides damit verbunden, daß die vorangegangene Zeit in goldenem Licht erscheint: Das ist das Athen des Perikles, das Athen größter Macht und Leistungsfähigkeit (wie ja auch der Klassik).

Ein Sieger also, ein Besiegter; ganz glatt scheint Kosellecks These nicht aufzugehen. Andererseits scheint sich seine Frage gerade an Thukydides als höchst fruchtbar zu erweisen. Ähnliches mag sich zeigen, wenn man die von ihm behandelten andern Historiker genauer untersucht. Im Besiegtsein könnte also wirklich ein „unerschöpfliches Potential des Erkenntnisgewinns" enthalten sein. 
Vieles, was aus dieser Position heraus erarbeitet worden ist, ist längst Allgemeingut der Wissenschaft. Historiker sollten wissen, daß es stets anders kommt als gedacht (sonst könnten sie ja gleich Soziologen werden; oder Politiker). Die Frage ist, ob auch heute noch jene mächtigen Herausforderungen, die von einer Niederlage ausgehen können, zur Gewinnung neuer Erkenntnisse und Methoden zu animieren vermögen. Wie steht es da etwa um die Niederlagen der Deutschen im zwanzigsten Jahrhundert?

Sieg und Niederlage finden heute neue Aufmerksamkeit. Die Niederlage Preußens 1806 zum Beispiel und was die Preußen daraus gemacht haben. Die Niederlage Frankreichs 1871, in der es sich unter anderm an den Preußen neu orientierte. Umgekehrt der Sieg Preußen-Deutschlands 1871. Jacob Burckhardt hat er tief erschüttert. „Vae victoribus" hat man es damals rufen hören - was sich leider bald bewahrheiten sollte.

Vielleicht belebt sich das Interesse, ja die neue Wertschätzung der Niederlage nicht zufällig etwa zur gleichen Zeit, da man die Opferrolle (freilich nachträglich) gegenüber der des Täters aufwertet; da man etwa - wie beim Kampf um das Vertriebenenzentrum hautnah zu spüren - das eigene Monopol auf den Opferstatus eifersüchtig verteidigt.

Was bei einer großen Niederlage verpaßt werden und was das für Konsequenzen haben kann, ist offensichtlich, wenn man an die deutsche Niederlage von 1918 denkt. Man weiß ja nicht, was es bewirkt hätte, aber an sich hätte sich deutschen Historikern im Gefolge des Thukydides doch wohl die Aufgabe gestellt, sowohl den Ausbruch des Kriegs wie die Gründe der Niederlage so intensiv zu erforschen, daß, wie ich vermute, herausgekommen wäre, daß diese Niederlage zumindest von irgendeinem Zeitpunkt an unvermeidlich und schließlich mit gutem Grund erlitten worden ist. Dazu hätte es gar nicht großer Geschichtsschreibung bedurft. Gründliche Untersuchungen und Monographien hätten es auch getan. Doch bewegte man sich ja auf anderen Bahnen.

Gewiß kann man einwenden, es sei nicht unbedingt geboten, sich mit einer Niederlage abzufinden. Und schon gar nicht ist, zumindest grundsätzlich, gesagt, daß der letztlich Stärkere unbedingt auch der Bessere ist. In seinem Gedicht „Pharsalia“ hat Lucan in der Mitte des ersten Jahrhunderts n. Chr. angesichts des Sieges, den Caesar einst über die Römische Republik erfocht, den berühmten Vers gedichtet: „victrix causa deis placuit, sed victa Catoni“: Gegen die Götter, denen Caesars Causa gefiel, bot er also den jüngeren Cato auf, den hochverdienten Vorkämpfer der Republik. Diese Republik war nicht mehr zu halten, die Monarchie unausweichlich, wenn das Imperium fortbestehen wollte. Aber immerhin: Welches war eigentlich 
die legitime, die bessere Seite - aus der Perspektive römischer Aristokraten auch noch der frühen Kaiserzeit?

Wenn jedoch der Sieger auch nicht der Bessere sein muß, so ist er doch nach Aristoteles dem Besiegten „in irgendeiner Hinsicht an Trefflichkeit überlegen". Und dies eben herauszuarbeiten - und sei es herauszuarbeiten, daß der Sieger mit den Möglichkeiten der Zeit auf besserem Fuße steht -, sollte gerade dann den Besiegten von Nutzen sein, wenn sie ihre Niederlage wieder auswetzen wollen. Es könnte dazu dienen, daß sie sich in der verwandelten Welt zurecht- und das heißt doch wohl zugleich: zu Recht finden. Ohne Scheuklappen. Und indem sie vieles neu lernen. Wenn Historiker auch als Zeitgenossen eine Verantwortung haben, so ist sie hier nicht (oder bei weitem nicht in ausreichendem Maße) wahrgenommen worden.

1945 dagegen konnte weder die Kriegsursache noch der Grund der Niederlage, aufs ganze gesehen, sonderlich problematisch sein. Um so mehr waren es die namenlosen Großverbrechen, insbesondere der Mord an den Juden. Sie sind sowohl Teil des Kriegs gewesen als auch Fortsetzung einer anderen Serie von Niederlagen, die im nachhinein in die politisch-militärische mit einging; jener Niederlagen nämlich, die die deutsche Gesellschaft sich seit 1933 hatte beibringen lassen und vielfach auch selbst beigebracht hatte, indem sie es sich gefallen ließ, daß Grundpfeiler ihres rechtlichsittlichen Gefüges zum Einsturz gebracht wurden.

Wo Großverbrechen von solch riesigem Ausmaß begangen wurden, muß sich unweigerlich die Frage nach der Verantwortung aller Teile der Gesellschaft stellen, nicht nur der Führung sowie der engeren und weiteren Kreise ihrer Exekutoren. Denn allen zusammen hat dieses Regime die Komplizenschaft aufgenötigt. Das Problem liegt doch gerade darin, wie in einer Gesellschaft, die keineswegs überwiegend aus Schweinen und Schurken bestand, eine solche Ungeheuerlichkeit möglich wurde.

Die Geschichte dieses Krieges muß sich also in viele Dimensionen erstrecken. Sie kann nicht von einer Würdigung des vielfach unermeßlichen Leids der Opfer absehen. Sie muß aber auch zwischen den verschiedenen Teilen der Gesellschaft differenzieren. Wobei es nicht um Unterschiede nach Stand oder Klasse, Institution, Beruf oder Bildung geht; denn das Versagen und Mitmachen erstreckte sich ja überall hin. Nein, Unterschiede sind zu machen nach der Verknüpfung der Einzelnen in das Regime und seine Untaten. Es wäre an typischen Beispielen aufzuweisen, wie unterschiedlich alles war. Hier die Bereitwilligkeit, mitzumachen, handelnd, gewährend, zuarbeitend, zu- und wegschauend, sich anheimgebend den Befehlen, Zumutungen und Suggestionen. Dort die gar nicht so seltenen Versuche, Distanz zu halten, seine Pflicht (nicht nur Befehls-, sondern auch ethischen 
Grundsätzen gemäß) zu erfüllen, zumindest im eigenen Umkreis ehrenvoll, anständig, tapfer, ja auch mit Zivilcourage. Es ginge um die, natürlich auch im Wechsel befindlichen, Weisen der weithin willigen, aber doch vielfach auch der zögernden, vielleicht gar widerstrebenden oder resistenten Beteiligung am Ganzen. Und es wären die vielfältigen Weisen der „Anstekkung" und zumal derer der Umsetzung vom Kleinen ins Große herauszuarbeiten, also Formen zu finden, um die Verzahnungen von Mikro- und Makrogeschichte deutlich zu machen. Wobei das hohe Maß der Nebenwirkungen ganz anders gemeinter Taten oder Unterlassungen deutlich werden müßte. Der ganze Widersinn, in den so viele verstrickt waren, müßte herauskommen; das ganze Ungenügen, die Ohnmacht, die Beeinträchtigungen menschlicher Autonomie deutlich werden; das Makabre auch, das etwa darin bestand, daß Soldaten für ein Land zu sterben hatten, das von der eigenen Führung verraten wurde. Denn es waren ja keineswegs Nazi-, sondern deutsche Armeen, die kämpften; die vom Regime in Anspruch genommen wurden, vielfach, zunächst jedenfalls, im guten Glauben, ihre Pflicht für das Land zu tun.

Will man verstehen, was dieses Volk tat oder unterließ, muß man zudem all das Wissen, das wir inzwischen von den ungeheuerlichen Verbrechen, übrigens auch der Besatzungspolitik (nicht zuletzt in Polen) haben, deutlich konfrontieren mit dem, das die Damaligen hatten und zu haben vermochten, sowie von der Rolle, die es in den „évidences des acteurs" (R. Aron), in den Horizonten des Denkens spielen konnte. Wohl nirgends sonst in der Weltgeschichte klaffen so tiefe Abgründe zwischen dem, was die Mitwelt, und dem, was die Nachwelt weiß, kann und ist.

Man darf nichts verschweigen, nichts beschönigen, muß den Opfern gerecht werden. Man muß alle Versuchungen zur Apologetik durchstoßen, muß klar in der Verurteilung alles zu Verurteilenden sein, aber eben auch verstehen, was gerechterweise zu verstehen ist, und vor allem: all das Verschiedene in seine Zusammenhänge bringen.

Eine solche Geschichte konnte in den ersten Jahrzehnten nach dem Krieg schon deswegen nicht geschrieben werden, weil einerseits die Verdrängungen zu stark waren, auch die apologetischen Tendenzen, andererseits der Bruch zu tief. Nach allem, was dieser Krieg auch die Deutschen gekostet hatte, war es schwer zu verfechten, daß sie ihn gar nicht hätten gewinnen dürfen. Man rettete sich in die unengagierte Betrachtung: „Welches Geschichtsbuch man auch aufschlägt: Wenn das Dritte Reich beginnt, geht der Autor auf Distanz", hat Martin Broszat 1985 festgestellt. Man spricht wie von einer fernen Population. Unter diesen Umständen kann der Besiegtenstatus seine Fruchtbarkeit nicht entfalten. 
Später trat an dessen Stelle zunächst der Status des Befreiten. Wo sich die Zugänge zu den Quellen reichlich auftaten, deckte der Schutzschild schuldbeflissener Betroffenheit die offenen Flanken ab. Die Forschung ist lange schon in vollem Gange, gerade auch mikrohistorisch ist vieles erarbeitet worden. Manches davon ist auch schon früh Gegenstand literarischen Erzählens gewesen. Eine große Erzählung aber, wie sie etwa Wassilij Grossman in seinem Buch „Leben und Schicksal“ für die Sowjetunion unternahm, ist ausgeblieben. Und eine große wissenschaftliche Erzählung hat nur das Schicksal der Juden im Dritten Reich, aus der Feder Saul Friedländers, erhalten. Ist es zu gewagt, wenn man vermutet, daß das Erkenntnispotential der Niederlage von 1945 historiographisch noch keineswegs ausgeschöpft ist?

Wieder anders stellt sich die Niederlage der DDR 1989 dar. Jedenfalls für die, die sie als solche empfanden (und es noch oder wieder tun - zum Teil aus der nachgeholten DDR-Identität heraus, die sich so eigentümlich angesichts der westlichen Sieger und der von ihnen begründeten Verhältnisse ergab). Vieles ist einfacher: Kein Krieg, kein Auschwitz. Und zweifellos wird man vieles nicht verstehen können, wenn man nicht auch die vielfältige menschliche Bewährung unter zum Teil schwierigsten Verhältnissen berücksichtigt. Sie gehörte für nicht wenige zu den Bedingungen des notwendigen Sich-Einstellens auf die Gegebenheiten. Aber daneben steht eben unendlich viel Unrecht und Bedrückung, steht eine Verkürzung weiter Teile der Gesellschaft in ihren Entfaltungsmöglichkeiten (die sich nach der Niederlage teilweise zu perpetuieren scheint, um diese Niederlage gar nicht erst gehörig als Problem erscheinen zu lassen).

Das Scheitern dieses Staates, der sich ironischerweise zu den „Siegern der Geschichte" zählte, zu verstehen, ist vermutlich nur unter Niederringung zahlreicher Illusionen - oder besser: in offener Auseinandersetzung mit ihnen - möglich, die sich noch heute mit seiner Idee verbinden. Zumal die Sieger ja keineswegs in allem überzeugend sind. Will man sich wie einst Thukydides dazu durchkämpfen, die Niederlage zu verstehen, so muß man nicht nur in der Lage sein, sich selbst in Frage zu stellen, ganz und gar auf Erkenntnis statt auf das Hegen liebgewordener Abwehrmechanismen zu setzen, sondern auch Mittel und Wege zu finden, um im großen wie im kleinen (ganz entsprechend der Struktur dieser Gesellschaft) nachzuweisen, warum es 1989 mit rechten Dingen zuging. Freilich, der Besiegtenstatus muß als große Herausforderung in einem arbeiten. Dazu darf man nicht von außen kommen. Eine Geschichte der DDR, die die Vorzüge der Besiegtengeschichte voll ausschöpfen könnte, dürfte nicht vom Standpunkt der westdeutschen Sieger geschrieben werden. 
Aber vielleicht ist eine derart existentiell bestimmte Geschichtsschreibung heute zu schwer und sind die Historiker zu sehr in ihren Diskursen befangen, um sich noch solchen Herausforderungen ausgesetzt zu sehen?

Schließlich noch wenige Hinweise auf einen dritten antiken Historiker. Lichtenberg hat ihn „einen der ersten Schriftsteller, die je gelebt haben“, genannt. Um ihn zu verstehen, müsse man mehr als Latein wissen. „Was kann besser gesagt werden als was Tacitus“, denn um den handelt es sich, „von den Römern in einer gewissen Zeit sagt: Is habitus animorum fuit, ut pessimum facinus auderent pauci, plures vellent, omnes paterentur". Man sieht, von gewissen Aspekten unseres Themas verstand Lichtenberg etwas, denn Tacitus' Worte heißen auf deutsch: Das Dichten und Trachten befand sich in einer solchen Lage, daß wenige das schlimmste Verbrechen wagten, mehrere es wollten und alle es duldeten.

Lichtenberg spricht von dem „Heiden Tacitus, der mit jüdischer Finesse in jeder Handlung bis auf den Teufel hinunter sah". Dieser Historiker hat gelitten unter einer Dauerniederlage: Er gehörte dem stolzen römischen Senat an, den die Monarchie besiegt hatte, wie es den Göttern gefiel. Der Senat bestand fort als Quelle der Legitimität - aber unter dem Damoklesschwert des Machthabers, der ihn brauchte, der sich aber nur allzu leicht von ihm bedroht oder zumindest gestört fühlte, so daß er immer wieder Senatoren demütigte, vor sein Strafgericht zog (respektive durch die Standesgenossen verurteilen ließ), sie verbannte, mordete oder zum Selbstmord nötigte. Alle Selbstbehauptung, alles Wesen der Senatoren vollzog sich unter den Bedingungen steter Angst, des Mißtrauens, also auch der Anschwärzung, der Verdächtigung, des vorauseilenden Gehorsams und der nur allzu beliebten Katzbuckelei. Ständig war zu tun, was nicht zu verantworten war. Man machte Konzession auf Konzession, um schließlich doch dran glauben zu müssen. Vielfach jedenfalls. Gelegenheit genug also zum Studium des Menschen in der Spannung zwischen Stolz und äußerster Preisgegebenheit - wo man in der Tat bis auf den Teufel hinuntersah. Gelegenheit aber auch, um das Beispiel der Freigelassenen Epicharis zu zeichnen, die den grausamsten Foltern bis zum Tode trotzte, während vornehme Männer aus Angst die ihnen liebsten Menschen verrieten.

Alfred Heuß, um einen anderen Göttinger zu zitieren, hat Tacitus' Geschichtsschreibung eine Selbstbefreiung genannt. Viktor Pöschl sprach von der „sublimen Rache“, die er nahm; für alles, was er - mitgemacht hatte.

Über die Erfahrungen seiner Generation unter dem besonders üblen Kaiser Domitian berichtet er: „[... ] man verbannte jede edle Wissenschaft, damit wir nirgends mehr auf Ehrenhaftes stießen. Und in der Tat, wir 
gaben den stärksten Beweis von Hinnahmebereitschaft [... ], erfuhren, was das Äußerste an Knechtschaft ist, nachdem man uns durch Bespitzelung den Gebrauch der Sprache und des Gehörs genommen hatte. Wir hätten mit der Stimme selbst das Erinnerungsvermögen drangegeben, wenn so wie das Schweigen auch das Vergessen in unserer Macht läge“. Die Überlebenden hätten „sozusagen nicht nur die andern, sondern auch sich selbst überlebt. Sind doch so viele Jahre mitten aus unserm Leben herausgerissen, in denen wir zum Schweigen verurteilt waren, während wir Jüngeren alt wurden und die Alten fast an den Rand des Grabes gelangt sind“. Eine wundervolle Beobachtung. So spricht ein Historiker, der lange auf der Seite der Besiegten stand - speziell jenes Genus der Besiegten, die immer neu besiegt werden in ihrer Menschenwürde und ihrem Anstand, typischer Besiegter des 20. Jahrhunderts, aber eben auch der römischen Kaiserzeit ein Historiker, der sich einschließt in deren Reihen und versucht, mit seiner Niederlage wenigstens historiographisch fertigzuwerden, und zwar auf kaum zu übertreffende Weise. Er weiß, er zieht die Mißgunst derer auf sich, die „die Schilderung der Schandtaten anderer als Vorwurf gegen sich selbst empfinden, da sie sich ähnliches haben zuschulden kommen lassen“"

Unter diesen Umständen hielt Tacitus es für notwendig, die Maßstäbe aufrechtzuerhalten, ja einzuschärfen, Tugenden dürfen nicht verschwiegen werden. Und der Neigung zu verwerflichem Tun und Reden muß die Angst entgegengesetzt werden, die aus dem Gedanken an Nachwelt und Schande erwächst. Das Versagen darf nicht relativierend weggebügelt werden. Freilich, das ist aus der Position eines Aristokraten (eines auch an seinen Standesgenossen verzweifelnden, aber immerhin noch aus aristokratischem Anspruch heraus urteilenden) geschrieben. Aber läßt sich dergleichen nicht doch verallgemeinern? Was mit so einem Werk erreicht wird, mag zweifelhaft sein. Doch muß ja die Verantwortung auch des Historikers nach Maßgabe eines Als-Ob ausgeübt werden; als ob es auf einen wirklich ankäme.

\section{Hinweise}

Der Text, der dem Vortrag zugrundelag, ist überarbeitet und dabei erweitert worden.

Carl Schmitt: Ex Captivitate Salus. Köln 1950. 32. (Es handelt sich um den vierten Abschnitt des „Historiographia in Nuce: Alexis de Tocqueville“ überschriebenen Aufsatzes vom Sommer 1946. In meinem Exemplar trägt er die von C.S. handschriftlich hinzugefügte Überschrift: „Der Besiegte schreibt die Geschichte“. Ich habe das aufgenommen, freilich nur skizzenhaft: Handeln und Aushalten. In: K.-H. Bender/ K. Berger/M. Wandruszka, Imago Linguae. München 1977. 371 f. Vierzig Jahre nach Auschwitz. 2. Aufl. 1990. 134. 
Das vollständige Guizot-Zitat (C.S. hat das Wort aristocrate ausgelassen) bei SainteBeuve, Nouveaux Lundis. Bd. 2. Paris 1868.306. Guizot habe es im Parlament gesagt. Überliefert ist aber auch ein Brief, den er an Tocqueville am 30. Juni 1856 schrieb, in dem es heißt: Vous peignez et vous jugez la démocratie moderne en aristocrate vaincu et convaincu que son vainqueur à raison (s. Lucien Jaume, Tocqueville. Les Sources Aristocratiques de la Liberté. Paris 2008. 384.)

Koselleck: Erfahrungswandel und Methodenwechsel. Eine historisch-anthropologische Skizze. In: Ch.M./J. Rüsen, Historische Methode. München 1988. 13 ff. Dort Abschnitt fünf (51 ff.): Die Geschichte der Sieger - eine Historie der Besiegten. Wiederabdruck: R.K., Zeitschichten. Studien zur Historik. Frankfurt 2000. 27 ff. Darin $67 \mathrm{ff}$.

Bei Hans-J. Misselwitz, Nicht länger mit dem Gesicht nach Westen. Berlin 1996. 37, finde ich: „Wenn Siegen wirklich dumm macht, wie ein alter Spruch sagt [... $]^{\text {. }}$

Interesse der Fachleute: Das findet sich schon bei Johann Martin Chladenius in seiner Allgemeinen Geschichtswissenschaft, Leipzig 1752. Neudruck Wien/Köln/Graz 1985. 91 ff. 115 ff. 150 ff. Er führt als „Sehepunkte“ an: Religion, Vaterland, Familie, Stand, Freund/Feind, Vertraut/Fremd, Gelehrter/Ungelehrter, Betrübter/Fröhlicher. Sieger/Besiegter fehlt.

Boulainvilliers: Zitat aus dem Manuskript von Angoulème bei F. Furet/M. Ozouf, Deux Légitimations Historiques de la Société Française au XVIII ${ }^{\mathrm{e}}$ siècle. Mably et B. In: Annales 34, 1979, 442.

Raulff: U.R., Ein Historiker im 20. Jahrhundert: Marc Bloch. Frankfurt 1995.

„Kultur der Niederlage“ ist der Titel des Buches von Jürgen Schivelbusch. Berlin 2002. „Penser la Défaite“ heißt eine Aufsatzsammlung, die P. Laborie und P. Cabanel herausgegeben haben. Toulouse 2002. Von Geschichtsschreibung ist weder hier noch dort die Rede.

Leserbriefe: Jüngstes Beispiel FAZ 14.7.2009.

Orwell: Tribune 4.2.1944.

Churchill: Max Hastings, History as written by the victor (Rezension von David Reynold, Command of History). Veröffentlicht am 2.November 2004. Online im Internet: http://www.telegraph.co.uk/culture/books/3626376/History-as-written-by-thevictor.html (Stand: 19.10.2009)

Burckhardt: Briefe an seinen Freund Friedrich von Preen 1864/1893. Stuttgart/Berlin 1922. $63 \mathrm{f}$.

Nietzsche: Wir Philologen. In: F.N., Unzeitgemäße Betrachtungen. Stuttgart 1964. 582. Mann: Deutsche Geschichte des 19. und 20. Jahrhunderts. Frankfurt 1958. 820.

Orosius: Historiae adversus paganos 3,20.

Herodot: Meine Argumente dafür, worin das Neue seines Ansatzes bestand, habe ich (samt weiteren Hinweisen) vorgebracht in einem Aufsatz unter dem Titel: Die Entstehung der Historie, wieder abgedruckt in: C.M., Die Entstehung des Politischen bei den Griechen. Frankfurt 1980 u. ö. 360 ff. Zuletzt zum Thema: Die Entdeckung der Ereignisgeschichte bei Herodot. In: Storia della storiografia 10, 1986, 5 ff. Einiges würde ich heute etwas anders sehen. Das Entscheidende ist im Text weiter zugespitzt, um das Besondere der Griechen noch schärfer zu fassen. Wir finden hier wirklich etwas ganz Neues. Man sollte das nicht übersehen, indem man es von heute her unterschätzt oder auch indem man (Selbst-) Aussagen orientalischer Könige über ihre 
Großtaten, über einzelne Schlachten, vielleicht auch einmal über das Verschulden eines Vorgängers als Vorläufer oder frühe Stufen der Historie ansieht. Es ist einfach falsch, Verschiedenerlei, was erst im neuzeitlichen Geschichtsbegriff unter ein Dach gekommen ist, als von vornherein zusammengehörig anzusehen; so daß dann dieses oder jenes für frühe Zeiten als Ausdruck ein und derselben Sache erscheint. Man sollte die Besonderheit der Griechen viel elementarer ansetzen, als das nach einer langen Tradition scheinbar vertrauten Umgangs mit ihnen weithin üblich geworden ist. Vgl. auch C.M., Wandel ohne Geschichtsbewußtsein - ein Paradox unserer Zeit? Basel 2004. $10 \mathrm{ff}$.

Thukydides: Tyrannis Athens: 2,63,2 - Haß auf die Stadt: 1,75,4 (vgl. 76,1). 2,63,1 f., dort auch die Furcht vor Rache. 2,64,5. Vgl. Herodot 7,139,1 - Kriegsplan: 1,143,5 ff. 2,65 - Athens Mittel: 2,65,13. 2,13,2 f. Vgl. 1,141,5. 7,28,3 f. - ho parálogos: 1,78,1. 2,61,3. 85,2. 3,16,2. 7,28,3. 55,1. 61,3. 8,24,5 - nie läuft ...: 1,21,1 Vgl. 1,78,2. 140,1 - próphasis: G. Rechenauer, Thukydides und die hippokratische Medizin. Hildesheim u.a. 1991 - Politiker nach Perikles: 2,65 - Notwendigkeit, die Herrschaft zu behaupten: s.o.: Haß auf Athen. Furcht vor Rache. Für Athen stellt sich die Frage: Herrschen oder selbst beherrscht werden: 1,76,1 6,18,2 f. - Menschennatur: 1,75,3. 76,2 u.ö. - Heranzuziehen auch die Aussagen über das Recht des Stärkeren: 1,76,2. 4,61,5. 5,105,2 - prágmata: 1,89,1 (vgl. 1,75,2) - Dynamik Athens. Erfolg und Zuversicht: 1,70. 4,65,4 (vgl. 17,4). 6,9,3 (vgl. 11,5 f.). 6,18 - Im Genuß . . : 4,65,4. Man hat wenig Aussicht ...: 6,9,3 - Alkibiades: 6,15 ff. Bes. 18,6 f. - Pathologie: 3,82 Möglicher Erfolg in Sizilien: 2,65,11 (vgl. 6,15) - Karthago: 6,15,2. 90,2. Vgl. 34,2 Melierdialog: 5,85 ff. - Reden bei Thukydides: 1,22,1 - Sizilien: Aufbruch: 6,30 ff. Ende: 7,75/87 (dort auch das Zitat über das Ausmaß der Niederlage) - Abfall der Verbündeten: 8,1,2. 8,2.

Zur Kluft zwischen der Ebene des menschlichen Handelns und tieferen prozessualen Zusammenhängen: R. Aron, Thucydide et le Récit Historique. In: R.A., Dimensions de la Conscience Historique. Paris 1961. 147 ff. Vgl. die entfernten Entsprechungen, die F. Furet bei Tocqueville entdeckt hat: 1789 - Vom Ereignis zum Gegenstand der Geschichtswissenschaft. Frankfurt/Berlin/Wien 1980.25.32 f.

$\mathrm{Zu}$ Thukydides' Arrangements sowie zum Verhältnis zwischen Ausgesprochenem und Verschwiegenem: K. Reinhardt, Thukydides und Machiavelli. In: K.R., Vermächtnis der Antike. Göttingen 2. Aufl. 1966. 184 ff.

Hegel: Vorlesungen über die Philosophie der Weltgeschichte. 2. Aufl. Hamburg 1923. 636.

Frankreich/Preußen: Raulff (wie o.) $35 \mathrm{f}$.

J. Burckhardt: W. Kaegi, Jacob Burckhardt. Eine Biographie. Bd. 5. 1973. 473 ff.

Vae victoribus: Schivelbusch (wie o.) $150 \mathrm{f}$. Vgl. $32 \mathrm{f}$.

Zur Aufwertung der Opfer: Ein sehr früher Beleg dafür: Ivo Andrić, Über allen Siegen. 1920.: In: Serbische Avantgarde 1918/39: „Euer Sieg hat eine niedrige Stirn und rote Augen. Der Sieger hat einen unruhigen Blick. Verflucht ist euer feuriger Wein des Sieges. Oh, der erquickt nicht und macht auch nicht fröhlich! - Gott hält seine Hand über den Scheitel der Besiegten, und der Sieger ist allein, und seine Freude lodert auf und verlöscht. Alles, was an Hoffnung, Trost und Schönheit auf der Welt ist, enthüllt sich den Augen der Besiegten; die Sieger sind blind, sie zittern und stehen in Flammen, und haben nichts außer ihrer wilden Flamme der Freude, von der nichts 
bleibt als Asche. - Denn was sind die Siege von heute anderes als die Niederlagen von morgen? In den Augen des Menschen, des Alleingelassenen gibt es weder gewonnene noch verlorene Schlachten, sondern in allen Kriegen, ob gewonnen oder verloren, immer nur eine besiegte Menschheit... Es gibt keine Niederlagen und keine Siege, sondern immer nur und überall bei den Besiegten wie bei den Siegern den gequälten und erniedrigten Menschen".

Niederlage von 1918: Eduard Meyer ist in seiner Rektoratsrede in Berlin am 15.10.1919 (Kleine Schriften II. Halle 1924. 539 ff.) unter dem frischen Eindruck der Niederlage ausführlich aufThukydides eingegangen. Er spricht von der Ähnlichkeit des Schicksals Deutschlands mit dem Athens im Peloponnesischen Krieg. Er bemerkt, den Athenern habe ein Perikles so gefehlt wie den Deutschen ein Bismarck. Zeitweilig erweckt Meyer den Eindruck, in Thukydides' Bericht über den Krieg seien direkte Parallelen zu finden, wenn er etwa von der „kaum begreiflichen Verblendung“ spricht. Aber kein Wort darüber fällt, was es bedeutete, daß Thukydides als Besiegter, als Infragegestellter solange an sich und der Materie arbeitete, bis er erkannte, daß es bei der Niederlage mit rechten Dingen zugegangen ist. Was sich entsprechend für die Deutschen empfohlen haben könnte. Zu seiner Haltung im Krieg: J. von Ungern-Sternberg, Politik und Geschichte. Der Althistoriker Eduard Meyer im Ersten Weltkrieg. In: W.M. Calder III./A. Demandt, Eduard Meyer. Leiden u.a. 1990. $484 \mathrm{ff.}$

Victrix ... : Lucan, Pharsalia 1,128.

Aristoteles: Politik 1255 a 15.

Aron: (wie o.) 180.

Broszat: M.B., Nach Hitler. Der schwierige Umgang mit unserer Geschichte. München 1986. 161. Ähnlich auch: I. Fetscher. In: J. Habermas, Stichworte zur geistigen Situation der Zeit. Frankfurt 1979. $122 \mathrm{f}$.

Friedländer: S.F., Das Dritte Reich und die Juden I. II. Sonderausgabe. München 2007. Lichtenberg: G.Ch.L., Sudelbücher. München 2005. E 197 - 178 -18 - 181.

Epicharis: Tacitus, Annalen 15,57.

Tacitus: Is habitus: Historien 1,28 - Man verbannte ... Agricola 2,2 f. - Die Überlebenden ... : ebd. 3,2 - Schilderung der Schandtaten . . . : Annalen 4,34,4-Maßstäbe ebd. 3,65 .

Heuß: A.H., Gesammelte Schriften in drei Bänden. Stuttgart 1995. II 1476.

Pöschl: V.P., Das Bild der politischen Welt bei Tacitus. In: Tacitus, Historien übersetzt von W. Sontheimer. Stuttgart 1959. xxviii.

Die entgegengesetzte Konsequenz zieht der Lehrer Gu in Yiyun Li, Die Sterblichen. München 2009: Seine Tochter wäre nie eine glühende Mao-Anhängerin geworden, „wenn sie die verlockenden Sprüche der Kulturrevolution nicht hätte lesen können; und sie wäre nicht verhaftet worden, als sie ihre Zweifel anmeldete, hätte er ihr nicht beigebracht, selbständig zu denken, statt den Argumenten der Masse zu folgen“. Also ist zu wünschen, daß Kinder nichts lernen.

Für nützliche Hinweise danke ich Hinnerk Bruhns, Marlene Hiller, Franziska Meier, Ulrich Raulff und Jürgen v. Ungern-Sternberg. 